\section{Gravidez de substituição}

\section{Surrogate pregnancy}

Otávio Marambaia dos Santos 1

\begin{abstract}
Applied medical science and technology have now created the conditions where it is possible for infertile couples, who would previously have been condemned not to have children by the usual biological means, to achieve this objective. First, stunning scientific advances in medically assisted reproduction have made it possible to overcome infertility arising from insufficient ovulation or low sperm-count by way of in vitro fertilization. Secondly, the embryo thus produced can now be implanted in another woman's uterus. This surrogate pregnancy has given rise to a number of ethical, religious and legal questions. On the one hand, the law has a relatively benign view of this practice-so long as it remains within the context of the conventional family structure. Likewise ethics has already marked out the stages in this process. Religious leaders, however, remain deeply opposed and unwilling to enter into dialogue on the issue. Although Brazil is the largest Catholic country in the world, increasing numbers of couples in this country are taking advantage of this new scientific resource, even though they are aware that it conflicts with official religious doctrine. Bioethical debate of this issue has only recently begun and needs to bear in mind the extent to which reproductive technology involves new groups who are not covered by the classical definition of the nuclear family.
\end{abstract}

Key words Replacement pregnancy, Surrogate motherhood, Heterologous reproduction
1 Programa de Doutoramento em Bioética. Faculdade de Medicina. Universidade do Porto. Alameda Prof. Hernâni Monteiro, 4200319. Porto, Portugal. E-mail: otaviomarambaia@hotmail.com

\section{Resumo}

A tecnologia e a ciência médica aplicada tem criado as condições para tornar possivel que casais inférteis, antes condenados a não ter filhos pelos meios biológicos usuais, hoje alcancem este objetivo. Os formidáveis progressos cientificos com a reprodução medicamente assistida, num primeiro momento, permitiram superar a infertilidade causada por ovulação insuficiente ou um número pequeno de espermatozóides com a fertilização in vitro. Num segundo momento, depois de gerado o embrião, implanta-lo no útero materno e, finalmente, conseguir a sua implantação em outro útero que não o da dona do embrião gerado em laboratório. Neste estágio - a gravidez de substituição - tem gerado inúmeros questionamentos de ordem ética e religiosa e jurídica. Se de um lado a lei já tem uma visão relativamente pacificada - dentro da ótica da estrutura familiar vigente - e os fóruns éticos já tenham definido deontologicamente os passos deste processo, o campo religioso continua postando-se de maneira contrária e com uma abertura muito estreita para discussões sobre o tema. No maior país católico do mundo, no entanto, muitos casais - mesmo sabendo estar contrariando normas explicitadas por documentos eclesiásticos têm buscado, cada vez mais, este recurso que a ciência lhes põe a disposição.

Palavras-chave Gravidez de substituição, Maternidade substituta, Reprodução heteróloga 


\section{Introdução}

A tecnologia e o progresso científico, galopantes em seu ritmo de impor novidades, são também elementos instigadores de novos e complexos dilemas éticos. Não se trata de discutir se os avanços até aqui conseguidos pelas novas técnicas e pela ciência são bons ou maus. Trata-se tão somente de refletir e ponderar eticamente os novos e delicados problemas que surgiram e surgem a cada dia, gerando situações antes impensáveis.

A assim chamada "reprodução medicamente assistida" pulou dos gradis de mero processo para corrigir falhas no processo "natural" da reprodução humana, para questões como mistura genética, manipulação genética - por muitos já rotulada de eugenismo; e chegando até a produção de clones, antes passando pela "criação" de indivíduos com a missão precípua de prover órgãos para transplantes. Em todas estas situações a dilemas éticos intricados a serem resolvidos. ${ }^{1}$ Há mais ou menos 50 anos tais situações pertenciam a úndécima prateleira dos sonhos, mitigados pela ficção científica literária e cinematográfica, tornando-se hoje parte do cotidiano das pessoas, porém propiciando a cada momento casos concretos a serem deslindados pela reflexão bioética. A discussão sobre a gravidez de substituição insere-se nestes casos concretos onde a cada dia novas e diferentes polêmicas surgem. No Brasil onde o aborto não é permitido, excetuando-se duas situações legalmente aceitas, - e onde só recentemente foi aprovado pelo Supremo Tribunal Federal a disponibilidade de embriões descartáveis em programas de reprodução assistida para a pesquisa científica, a gravidez de substituição ou "útero de aluguel" como popularmente é chamada entre nós, está liberada entre pessoas da mesma família até o segundo grau de parentesco ou, se aceito após consulta aos Conselhos Regionais de Medicina, a pessoas estranhas ao círculo familiar, desde que não envolvam acertos pecuniários. ${ }^{2}$

A alguns tais técnicas romperiam os dogmáticos conceitos normalmente levantados pela Igreja Católica que considera a gravidez fora do útero como antinatural e, portanto, despido dos aspectos sagrados que estas correntes advogam para a concepção. Respeitadas que sejam as crenças e os conceitos dos que assim pensam se tivermos que sacralizar algo, que seja a vida - que obtida desta ou daquela forma - é inegavelmente o que importa. Se considerarmos ainda que o mister natural proposto pela natureza é a perpetuação genética, não seria "antinatural" impedir a qualquer casal que possa ter corrigido um item que lhe impeça ter acesso a este “direito natural?" Como justificar a negativa de ter acesso a este recurso disponibilizado pela ciência?? Não estaria no mesmo plano negar-lhe acesso a terapias medicamentosas genéticas para cura de outras doenças ou mesmo impedir-lhe o acesso a um transplante de órgãos?

A participação piedosa e/ou solidária de um parente ou pessoa que se disponha a ceder seu corpo para a gravidez de uma mulher que esteja impossibilitada de tal, por problemas de saúde ou lesões irreversíveis no seu aparelho reprodutor, se justifica plenamente tendo em vista o preenchimento de uma vida sequiosa por amar outra. Esta vida querida e desejada, escolhida por decisão consciente, certamente não terá o comprometimento psicológico que os renitentes adversários desta possibilidade de reprodução alardeiam. ${ }^{3}$ Qual rebento teria mais dificuldades adaptativas: o filho ardentemente buscado e já amado, conseguido por esta via, hoje permitida pela ciência, ou aquele gerado sob circunstâncias as mais variadas, fruto de afetos ou desejos carnais eventuais, não desejado e não querido? Fico claramente inclinado a achar que filhos paridos por mães que não os desejam e mesmo os rejeitam terão, sem sombra de dúvidas, mais dificuldades que aqueloutros.

Há também os que levantam a bandeira da dignidade feminina, ultrajada que seria, transformando-se a mulher em mera "incubadora". Isto obviamente não corresponde aos fatos desde que não estejamos falando de uma indústria de reprodução em útero alheio por mulheres fúteis, com motivos idem, que comerciariam a gravidez sob a ótica da estética, por exemplo, para não "estragar" o corpo com uma gravidez e não da impossibilidade de uma gestação devido a graves dificuldades em seu corpo. Não se pode esquecer de que quem quer que se disponha a usar do seu corpo para o simples comércio, estaria em rota de colisão com todo o escopo ético que desenvolvemos até aqui. Não se pode esquecer, ainda, que mesmo solidária e não visando lucro com tal concessão, a mulher que livremente se dispõe a uma gestação para outrem tem, a nosso ver, necessidades que precisam ser supridas por quem será o beneficiário do seu sacrifício. Isto inclui as despesas médicas e outras surgidas pelas limitações que a gravidez impõe a mulher no seu dia a dia e no exercício de uma profissão. Não se pode falar em diminuição da dignidade feminina na gravidez de substituição quando a mulher que oferecerá seu útero tem respeitado a sua autonomia e autodeterminação e ela as exerce em sua plenitude. ${ }^{4}$

Há, por fim, os que se entrincheiram em aspectos jurídicos (mãe é aquela que pariu) e não avançam 
daí. 4 Não seria o caso agora de duvidarmos se nesta condição não estaríamos de fato reduzindo as mulheres à condição de meras "procriadoras"? Seria esta uma forma de conferir dignidade a figura da mulher? Certamente que não! Mãe pode e deve ser considerada também como aquela que cria! Tanto um filho saído do seu útero e com seus próprios cromossomos e do seu companheiro, quanto aquele gestado com suas características genéticas, mas em outro útero, conseguido pela solidariedade amorosa de um ente parental ou não.

\section{Gravidez de substituição e conflitos religiosos}

Ao decidir buscar os meios postos a sua disposição para a gestação de um filho fora do seu útero, a mulher fortifica a idéia de uma decisão relacional com o seu parceiro e nesta decisão está firmemente explicitado que estes progenitores assumem o compromisso com a nova vida a ser gerada. 5 Esta situação impõe ao casal o firme reconhecimento de suas responsabilidades com a vida a ser criada e para cujo desenvolvimento incorpora seus interesses e projeto de vida. Numa sociedade, no entanto em que a posição da principal confissão religiosa vê na condição do casal sem filhos um fatalismo intransponível - sem atentar para o que a ciência já superou - tratando a questão com a crueza dos indiferentes ou "donos da verdade", a discussão é difícil e resulta na busca da gravidez de substituição pelos atores envolvidos independentemente da resposta positiva ou não da hierarquia religiosa. 6

Malgrado hoje a Igreja tenha reconhecido algumas das "falhas" cometidas ao longo do tempo, um documento de 1987 emitido pela Congregação da Doutrina da Fé diz: "a maternidade substitutiva é contrária à unidade do matrimônio e à dignidade da procriação da pessoa humana". ${ }^{6}$ (p.30). Em outras palavras: a Igreja segue indiferente aos anseios dos casais aos quais a ciência possibilita hoje a geração de um filho. Nesta mesma publicação é dito que o casal que se dispõe a fazer tal tipo de procriação atenta contra a fidelidade conjugal, o amor materno e a "maternidade responsável". Vai mais além: ofende ao nascituro em sua dignidade e direitos além de instaurar a cizânia no seio da família. ${ }^{6}$

O Brasil, o assim chamado maior país católico do mundo, tem $70 \%$ da sua população (Instituto Brasileiro de Geografia e Estatística em 2008)7 professando o cristianismo católico, logo é de suma importância este documento para boa parte dos seus seguidores. Numa sociedade democrática e pluralista, no entanto os ditames da hierarquia são postos em cheque vez que não dá para se aceitar que alguém que muito deseja um filho seu e lança mão desta possibilidade conquistada pelo conhecimento humano esteja querendo-o para não lhe dar todo o amor e cuidado. Ou que o acerto entre o casal constitua um ato de infidelidade. A infidelidade não seria um fazer com o desconhecimento do outro? Como já dissemos no intróito: mãe que ardentemente deseja ter um filho já adredemente assume suas responsabilidades antes mesmo de vê-lo gerado. Falar que isto atenta contra a maternidade responsável é um argumento pífio e vazio. Por outro lado chamar de exclusivamente natural a forma clássica é desconhecer que a presença do homem no mundo, por mais que discutamos o seu intervencionismo na natureza, é "natural".

\section{Gravidez de substituição aspectos éticos e conflitos jurídicos}

O aparato legal vigente no Brasil sobre a gravidez de substituição é insuficiente para impedir o surgimento de conflitos de maternidade e paternidade. 8 De pronto o nascituro terá duas mães: a institucional, que cede o material genético, e a biológica ou receptora que o gesta. Pode também ter dois pais, um - se este for o marido de sua mãe e também doador do sêmen, e dois se se tratar de um doador anônimo. Pode, por fim, ter três pais e três mães: pai e mãe genéticos (doadores do óvulo e do sêmen); pai e mãe biológicos (se quem o gestou tiver marido) e pai e mãe institucionais (os que o encomendaram a uma clínica). Além desta multiplicidade de pais, ao considerarmos a extensão do direito à gravidez de substituição aos casais homoafetivos e pessoas solteiras de ambos os sexos não estaríamos, em contrário, privando a criança do direito de ter pai mãe? Tais situações estabelecem um emaranhado de situações suscitáveis judicialmente e de desfecho incógnito. Caberia a discussão de um novo estatuto da maternidade e paternidade?

$\mathrm{Na}$ letra fria da lei, em diversos países, é mãe aquela que pariu e deu a luz. Em outros países, onde a gravidez de substituição é praticada, as legislações muitas vezes divergem. Em Portugal o Código Civil, no art. 1.796, considera que o filho será do casal encomendante. Já a legislação sueca requer que o casal que idealizou a fertilização in vitro venha a adotar o bebê. Na Áustria há projeto dispondo que a mãe substituta não é obrigada a ceder a criança. Nos Estados Unidos há estrito respeito aos contratos firmados entre o encomendante e quem suportará a gestação substitutivamente. ${ }^{9}$ No Brasil há diversos projetos tramitando no Congresso Nacional ensejando ampla discussão, mas que se arrastam sem um 
horizonte previsível para sua aprovação. Recentemente o Conselho Federal de Medicina abriu ampla discussão, aberta aos que quiserem participar, de modo a prover o Brasil de uma nova resolução, buscando atender as novidades e interesses de uma sociedade plural e democrática. Nela já existe uma sugestão a ser discutida sobre a extensão do acesso ao direito da reprodução assistida para pessoas solteiras e para os que tenham relações homoafetivas. Propõe, no entanto, as mesmas restrições quanto ao âmbito da família parental e a excepcionalidade vigiada, fora disto, desde que não envolva transações pecuniárias.

Embora os documento legais no Brasil ainda não contemplem de maneira explícita as incontáveis situações decorrentes da gravidez de substituição e, até que tal aconteça, cremos que o legislador ou o aplicador do direito deveria optar pela presunção de paternidade para o casal que idealizou o filho ainda que o material genético não seja seu. $\mathrm{O}$ filho deve ser, portanto, daqueles que decidiram e quiseram o seu nascimento. ${ }^{9}$

O que é mais importante? Satisfazer a pessoa que não pode ter filhos pelos caminhos ditos "naturais" ou a criança que nascerá fruto da moderna tecnologia médica? A mãe e o pai doadores genéticos devem necessariamente ter vínculos afetivos, familiares ou genéticos com a receptora? Somente casais formalmente constituídos poderiam dispor destes recursos? Solteiras e solteiros, homossexuais ou não, teriam vez no uso destas novas tecnologias?10

Para tantas questões, e outras mais, não existem respostas prontas nem mesmo debate, ainda, sobre estes aspectos. Lembrar não custa, mas as principais correntes religiosas no Brasil ainda buscam argumentos contra a reprodução assistida dentro - e exclusivamente - do âmbito da estrutura familiar formal.

Obviamente não se pretende hierarquizar a discussão, mas há questões que a sociedade brasileira precisa avançar, como no debate resolutivo sobre a união homoafetiva e não ficar tão somente à mercê de resoluções, portarias ou decisões judiciais pontuais. Como dito, embora não seja precedente, é de bom alvitre atingirmos um consenso nesta seara antes de acrescentarmos algo que gera, literalmente, tantas inquirições e restrições mesmo que realizada dentro da família formal.

\section{Aspectos legais da gravidez de substituição no Brasil}

A gravidez de substituição do Brasil é permitida, entretanto tal permissão não consta em leis especí- ficas, mas em documentos com valor legal, como a Resolução do Conselho Federal de Medicina $n^{\circ}$ 1.358/1992 que diz no seu Inciso VII:

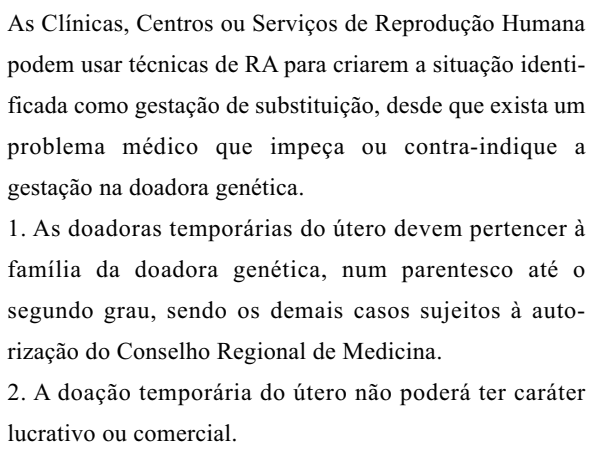

Ao estabelecer esta resolução, o Conselho Federal de Medicina do Brasil a estatuiu como norma deontológica e, por conseguinte, de cumprimento estrito pelos médicos. No Brasil a gravidez de substituição, atendidos os dispositivos proclamados pela resolução, é não apenas legal como ética. Felizmente entendeu-se o problema da infertilidade e o quanto esta condição perturba e prejudica a saúde da mulher e do casal e é como dano a saúde que é vista. Tanto para a mulher quanto para o homem, aí na condição de participante do casal. Seria absurdo, e injusto, impedir que estas pessoas com claras dificuldades biológicas tenham acesso àquilo que a ciência e a tecnologia põem à disposição. 10,11

O reparo e o limite seriam a mercantilização ou a utilização desta técnica da reprodução medicamente assistida para fins cosméticos e fúteis por mulheres aptas fisicamente para a procriação que assim se valeriam destes métodos como "produtos" à sua disposição. Não é ética esta utilização.11

\section{Considerações finais}

Sara, mulher do patriarca Abrão, era avançada em anos e nesta condição já estéril pelo envelhecimento, usou de um artifício do que poderíamos, grosso modo, chamar de uma gravidez de substituição rudimentar e primitiva: tomou sua escrava Agar e a fez deitar-se com o patriarca para que lhe gerasse um filho e assim possibilitasse o cumprimento da promessa divina. Sara, então, se imaginava incapaz de gerar filhos e só muito mais tarde viria a ter o seu próprio. A história é largamente conhecida e todos sabemos do desfecho considerado miraculoso da gravidez de Sara, já encanecida, cujo fruto seria Isaac.

A ciência desenvolveu-se de tal sorte que a cada dia mais e mais histórias, parecidas ou não com esta, 
se tornam realidade. A intensa vontade de Sara em ter um filho é exemplar para situações dos nossos dias. Quem poderia condená-la pelo desejo acendrado de ter o seu próprio filho? E nos dias de hoje, como se pode negar a uma mulher e um homem ou a um casal alcançar a tão desejada felicidade de perpetuar-se através de um filho? Se há recursos técnicos e se não há trânsito mercantil na iniciativa, como negar este direito fundamental da espécie humana? 12

Compreendo como justo e eticamente aceitável a possibilidade de propiciar-se as mulheres e famílias

\section{Referências}

1. Sagre M, Schramm FR. Quem tem medo das (bio) tecnologias de reprodução assistida? Rev Bioética. 2001; 9: 43-56.

2. Brasil. Conselho Federal de Medicina. Resolução n ${ }^{\circ} 1358$, de 11 de Novembro de 1992. Adota normas éticas para a utilização das técnicas de reprodução humana assistida. Diário Oficial da União. Brasília, DF; 19 nov. 1992. Seção 1. p. 16053

3. Costa SIF, Oselka G, Garrafa V, coordenadores. Iniciação à Bioética. Brasília, DF: Conselho Federal de Medicina; 1998

4. Mori M. Porque concordo com a sentença da Juíza Schettini acerca da "gravidez de aluguel. Bol Soc Bras Bioética. 2001; Ano II (4): 1/2.

5. Mori M. Fecundação assistida e liberdade de procriação. Rev Bioética. 2001; 9: 57-70.

6. Joseph Card. Ratzinger Documentos Pontifícios 213. Sobre o respeito à vida humana nascente e a dignidade da procriação. Instrução da Congregação da Doutrina da Fé. Petrópolis: Vozes; 1987.

Recebido em 29 de junho de 2010

Versão final apresentada em 13 de novembro de 2010

Aprovado em 30 de novembro de 2010 sem filhos a oportunidade de uma gravidez de substituição, atendidas as condições de não comercialização, sem acordos pecuniários, e observadas as absolutas dificuldades biológicas de quem desejando um filho o seu corpo lhe impeça.

Por fim, cremos que a discussão bioética está apenas começando, vez que a tecnologia da reprodução tem trazido ao centro do debate novos grupos que não se encaixam na definição clássica da família nuclear.

7. IBGE - Anuário estatístico do Brasil 2008 v.68, Brasília, 2008.

8. França GV. Direito Médico. São Paulo: Fundo Editorial BYK; 2001.

9. Diniz MH. O estado atual do biodireito. São Paulo: Saraiva; 2001.

10. Berlinguer G. Bioética cotidiana. Brasília: Editora Universidade de Brasília; 2004.

11. Pessini L, Barchifontaine CP. Fundamentos da bioética. São Paulo: Paulus; 1996.

12. Garrafa V, Costa SIF. A bioética no século XXI. Brasília: Editora Universidade de Brasília; 2000. 